\title{
Assessment of Non Coding RNA Expression as a Potential Stem Cell Biomarker in Breast Cancer
}

\author{
Naglaa A. ELaidy ${ }^{1}$, Eman M. Elsalahy, Marwa M. Sayed ${ }^{1}$, Mahmoud A. Mahmoud ${ }^{2}$ \\ ${ }^{1}$ Medical Biochemistry and Molecular Biology Department, ${ }^{2}$ General Surgery department Faculty of Medicine, Ain \\ Shams University \\ Corresponding author: Naglaa A. ELaidy, Email: Najlaa.elaidy@gmail.com, Mobile: 01211041669
}

\begin{abstract}
Background: worldwide, breast cancer is the most common malignancy among women and there is a deep need for precise novel methodologies for breast cancer (BC) diagnosis. Major advances in cancer control will be successfully achieved with early cancer detection. So, recent trends are going toward using circulating non-coding RNA as diagnostic tool for their critical role in cancer detection.

Aim: retrieve non coding RNA that is mechanistically linked to breast cancer stem cell with validation of the results in a group of breast cancer patients versus control groups to evaluate their usefulness as a potential biomarker in breast cancer diagnosis.

Patients and Methods: we retrieved LncRNA that is linked to stem cell differentiation and specific to BC utilizing bioinformatics tools. Then we validated this biomarker in serum of 30 patients with $\mathrm{BC}, 12$ patients with benign breast lesion and 12 healthy volunteers using RT-qPCR. We evaluate the power of diagnosis of the serum profiling system using ROC curve analysis.

Results: hoxd antisense growth-associated long non coding RNA (HAGLR) had great sensitivity and specificity for differentiating $\mathrm{BC}$ from patients with benign breast lesion and also from healthy controls.

Conclusion: the chosen circulatory RNA based biomarker can be used as a potential diagnostic biomarker for BC. In addition it could be therapeutic target.
\end{abstract}

Keywords: breast cancer, long non coding RNA, bioinformatics, diagnosis.

\section{INTRODUCTION}

Breast cancer is the most frequent malignancy among women worldwide. It can be treated when diagnosed at its earliest stage. Every 3 minutes a female is diagnosed with BC globally, accounting to one million cases every year ${ }^{(1)}$.

In Africa, there is a limited data about breast cancer incidence. The incidence rates for breast cancer between African countries vary considerably with the highest rates are in Gharbiah governorate (Egypt) [6078 cases reported in Egypt during the interval (1999-2007) and the lowest rates are in Ghana ${ }^{(2)}$.

When taking a clinical decision on $\mathrm{BC}$ treatment, Oncologists face an exceptionally hard task. Such hard task could be easier if there are strong diagnostic and prognostic factors, which guide the choices of treatment options ${ }^{(3)}$.Molecular technique, such non coding RNA (ncRNA) expression profile, has been used to improve $\mathrm{BC}$ diagnosis and to evaluate patient outcome and response to treatment ${ }^{(4)}$.

Recent evidence suggests that small populations of cancer stem cells can modify and influence neoplastic cells aggressiveness and behavior as well as response to therapy ${ }^{(5)}$.Many observations prove that $\mathrm{BC}$ ability to divide, progress and spread is based on this small subpopulation of cells with characteristics similar to stem cells, known as breast cancer stem cells $(\mathrm{BCSCs}){ }^{(6)}$. Several markers have been reported for identification of BCSCs in many cancers, such as CD44, CD133, CD24, EpCAM, CD47and $\operatorname{ALDH} 1^{(7)}$.

Stem cells undergo two types of cell division (symmetric and asymmetric), producing similar stem cell colony or more differentiated cells. Moreover, stem cells remain in a state of quiescence in the tumor environment, facilitating the so-called kinetic resistance, whereby these quiescent cells are unaffected by agents that can cause DNA damaging or radiation in comparison with the more rapidly proliferating cells ${ }^{(\mathbf{8})}$. Also great drug resistance has been described for Cancer stem cells (CSCs) through different mechanisms such as drug effluxing ${ }^{(9)}$.

In recent years, lncRNA is emerging as an important player in the cancer paradigm. These non coding RNAs are often apparently des-regulated in many types of human cancers ${ }^{(10)}$. Accumulating evidences provide a mechanistic insight on how IncRNAs regulate important signaling pathways in cancer cells at the transcriptional, post-transcriptional and epigenetic levels ${ }^{(\mathbf{1 1})}$.In addition to their effects on cancer cell growth, cell signaling and survival, IncRNA can modulate CSC behavior through the expression of pluripotency factors. The identification of IncRNAs that are linked to cancer stem cells differentiation and self-renewal provides new opportunities for cancer diagnosis and therapy ${ }^{(\mathbf{1 2})}$. 
Among the oncogenic lncRNAs is lincRNAHOTAIR (HOX antisense intergenic RNA), which is transcriped from the mammalian homeobox C (HOXC) gene locus on chromosome 12q13.13. HOTAIR is upregulated in primary and metastatic breast cancer ${ }^{(13)}$.

Aim: the aim of the study is to retrieve non coding RNA that is mechanistically linked to breast cancer stem cell with validation of the results in a group of breast cancer patients versus control groups to evaluate their usefulness as a potential biomarker in breast cancer diagnosis.

\section{PATIENTS AND METHODS}

\section{Patients and samples}

Thirty BC patients participated in this study; diagnosis is done according to histopathological techniques. BC patients were classified according to clinical stages into; 12 (40\%) stage I, 13(43.3\%) stage II and $5(16.7 \%)$ stage III carcinomas using the TNM classification American Joint Committee on Cancer, $2016^{(14)}$ and graded according to American Cancer Society, $2017^{(1)}$.We collected venous blood samples from patients before any therapeutic interventions, including radical mastectomy or modified radical mastectomy, radiotherapy and chemotherapy. We analyzed the serum samples of 30 $\mathrm{BC}, 12$ benign breast lesions and 12 healthy controls collected at general surgery department, Ain Shams University Hospital from June 2016 to November 2017.

Serum was obtained from each sample through centrifugation of venous blood samples collected from participants. All serum samples were kept at $-80^{\circ} \mathrm{C}$ for further analysis.

\section{Ethical and Approval Statements}

The study was approved by the Ethics Board of Ain Shams University, Faculty of Medicine, Egypt and an informed written consent was obtained from each participant in the study.

\section{Extraction of total RNA, including IncRNA}

MiRNeasy ${ }^{\circledR}$ RNA isolation mini kit (Qiagen ${ }^{\circledR}$, USA) was used to extract total RNA, including lncRNA from sera samples according to manufacturer's instructions. This is followed by reverse transcription of the extracted total RNA into cDNA with a miScriptRT II Kit (Qiagen ${ }^{\circledR}$, USA) following the manufacturer protocol for sera/tissue samples) using Hybaid thermal cycler (Thermo Electron Waltham, MA).

\section{Real time-PCR (qPCR) quantification of RNA based biomarker}

LncRNA-HAGLR expression in participant's serum was assessed using $\mathrm{RT}^{2} \mathrm{SYBR}$ Green ROX qPCR Mastermix on Step One Plus ${ }^{\text {TM }}$ System (Applied Biosystems Inc., Foster, CA).

GAPDH was used as an internal control. All the PCR primers were obtained from (Qiagen ${ }^{\circ}$, USA). Relative measurement of RNA based biomarker expression was figured using the $2^{-\Delta \Delta C t}$ technique. For normalization of raw data we used GAPDH as a housekeeping gene as the invariant control for the samples and compared with a reference sample.

The PCR program for Syber green based QPCR was as follow: at first, initial activation stepat $95^{\circ} \mathrm{C}$ for $10 \mathrm{~min}$; after that 40 cycles of denaturation for $15 \mathrm{sec}$ at $95^{\circ} \mathrm{C}$; then annealing for $30 \mathrm{sec}$ at $55^{\circ} \mathrm{C}$; lastly, extension for $30 \mathrm{sec}$ at $72^{\circ} \mathrm{C}$.

The threshold cycle $(\mathrm{Ct})$ value of each sample was calculated using StepOnePlus ${ }^{\mathrm{TM}}$ software v2.2.2 (Applied Biosystems). We used melting curve analysis software of Applied Biosystem to analyze our results. Amplification plots and Tm values were analyzed to affirm the specificities of the amplicons for Sybr Green -based PCR amplification.

\section{Statistics}

We used SPSS 20 to do all statistical analyses. Comparisons were done using MannWhitney, Krausakul Wallis, chi-square test, and oneway analysis of variance (ANOVA), as appropriate. To investigate the predictive value of chosen RNA based biomarker for $\mathrm{BC}$, we used the receiver operating characteristic (ROC) curve. We assessed the relation between RNA based biomarker expression and clinic-pathological parameters.

$P$ value $=$ level of significance, $P>0.05$ nonsignificant, $P<0.05$ significant, $P<0.01$ highly significant

\section{RESULTS}

The present study included 54 female subjects. They were classified into 3 groups:

\section{Group1: malignant breast cancer cases:}

$(n=30$, of mean age $54.9 \pm 14.5$ years, median 56 years and range from 20-81 years).

Group 2: benign breast cases diagnosed as fibroadenoma:

$(n=12$, of mean age $46.5 \pm 15.3$ years, median 52.5 years and range from 20-62years). 


\section{Group 3: healthy normal female individuals:}

$(n=12$, of mean age $50.7 \pm 11.6$ years, median 54.5 years, and range from 23-63 years).

Table (1): The Age in Different Groups of the Study in Years.

\begin{tabular}{|l|c|c|c|c|}
\hline \multicolumn{1}{|c|}{ Group } & no. & Median & Range & Mean \pm SD \\
\hline Malignant & 30 & 56 & $20-81$ & $54.9 \pm 14.5$ \\
\hline Benign & 12 & 52.5 & $20-62$ & $46.5 \pm 15.3$ \\
\hline Healthy normal & 12 & 54.5 & $23-63$ & $50.7 \pm 11.6$ \\
\hline
\end{tabular}

Table (2): Quantitative RT-PCR for Measurement of IncRNA-HAGLR Mean Rank of Sera Samples in the Malignant Group Compared to Benign and Normal Control Groups.

\begin{tabular}{|c|c|}
\hline Group & Quantitative IncRNA-HAGLR by RT PCR \\
\hline \multicolumn{2}{|l|}{ Malignant } \\
\hline Median & 0.4550 \\
\hline Range & $0.05-4.14$ \\
\hline Mean Ranks & 18.15 \\
\hline \multicolumn{2}{|l|}{ Benign } \\
\hline Median & 36.95 \\
\hline Range & $0.34-224.41$ \\
\hline Mean Ranks & 37.75 \\
\hline \multicolumn{2}{|l|}{ Normal control } \\
\hline Median & 4.91 \\
\hline Range & $0.85-265$ \\
\hline Mean Ranks & 40.63 \\
\hline $\mathrm{X}^{2}$ & 24.053 \\
\hline $\mathrm{P}$ & $0.000 * *$ \\
\hline
\end{tabular}

Krausakul Wallis Test, p $(>0.05)$ : not significant, $* p(<0.05)$ : significant, $* * p(<0.01)$ : highly significant

Using real-time PCR; the mean rank level for IncRNA-HAGLR RNA in the malignant group (Mean rank was 18.15) as compared to benign (Mean rank was 37.75) and normal control groups (Mean rank was 40.63) with high significant difference between the three groups $(\mathrm{P}<0.01)$ (Table 2).

Table (3): Quantitative RT-PCR for LncRNAHAGLR Comparison between Different Groups of the Study.

\begin{tabular}{|c|c|c|c|c|c|c|}
\hline \multirow{2}{*}{$\begin{array}{l}\text { Quantitative } \\
\text { IncRNA- } \\
\text { HAGLR by } \\
\text { RT PCR }\end{array}$} & \multicolumn{2}{|c|}{$\begin{array}{l}\text { Malignant and } \\
\text { benign groups }\end{array}$} & \multicolumn{2}{|c|}{$\begin{array}{l}\text { Malignant and } \\
\text { normal control } \\
\text { groups }\end{array}$} & \multicolumn{2}{|c|}{$\begin{array}{c}\text { Benign and } \\
\text { normal control } \\
\text { groups }\end{array}$} \\
\hline & Malignant & Benign & Malignant & $\begin{array}{l}\text { Normal } \\
\text { control } \\
\end{array}$ & Benign & $\begin{array}{l}\text { Normal } \\
\text { control }\end{array}$ \\
\hline $\begin{array}{c}\text { Mean rankfor } \\
\text { IncRNA- } \\
\text { HAGLR }\end{array}$ & 17.05 & 32.63 & 16.60 & 33.75 & 11.63 & 13.38 \\
\hline $\begin{array}{l}\chi 2: \\
(\mathrm{P})\end{array}$ & \multicolumn{2}{|c|}{$\begin{array}{c}46.5 \\
\mathrm{P}=(0.000)^{*} *\end{array}$} & \multicolumn{2}{|c|}{$\begin{array}{c}33 \\
\mathrm{P}=(0.000)\end{array}$} & \multicolumn{2}{|c|}{$\begin{array}{c}61.5 \\
\mathrm{P}=(0.544)\end{array}$} \\
\hline
\end{tabular}

Mann-Whitney test, $\mathrm{p}(>0.05)$ : not significant, $* \mathrm{p}(<0.05)$ : significant, **p $(<0.01)$ : highly significant

By applying post hoc test for lncRNAHAGLR, there was a highly significant difference between the malignant and benign groups $(\mathrm{p}<0.01)$ by using Mann-Whitney test $(\mathrm{U}=46.5)$. Also there was a highly significant difference between the malignant and normal control groups $(\mathrm{p}<0.01)$ and $(\mathrm{U}=33)$.

But there was no significant difference between the benign and normal control groups $(\mathrm{P}=$ 0.544) using Mann-Whitney test ( $U=61.5$ )(table 3).

Table (4): LncRNA-HAGLR Expression in Sera Samples in Relation to Clinicopathological Factors of Malignant Group ( $\mathrm{No}=30)$.

\begin{tabular}{|c|c|c|c|c|}
\hline \multirow{2}{*}{\multicolumn{2}{|c|}{ Clinicopathological factors }} & \multicolumn{3}{|c|}{ LncRNA-HAGLR expression } \\
\hline & & \multirow{2}{*}{$\begin{array}{c}\text { Positive(22) } \\
3(13.6 \%)\end{array}$} & \multirow{2}{*}{$\begin{array}{c}\text { Negative(8) } \\
1(12.5 \%)\end{array}$} & \multirow{3}{*}{$\begin{array}{c}\chi 2:(\mathbf{P}) \\
0.007 \\
P=(0.935)\end{array}$} \\
\hline \multirow{2}{*}{ Parity (30) } & Nullipara (4) & & & \\
\hline & \begin{tabular}{|l} 
Multipara (26) \\
\end{tabular} & $19(86.4 \%)$ & $7(87.5 \%)$ & \\
\hline \multirow{2}{*}{$\begin{array}{l}\text { Menopause } \\
\text { (30) }\end{array}$} & \begin{tabular}{|l|} 
Premenopause (9) \\
\end{tabular} & $5(22.7 \%)$ & $4(50.0 \%)$ & \multirow{2}{*}{$\begin{array}{c}2.078 \\
\mathrm{P}=(0.149)\end{array}$} \\
\hline & \begin{tabular}{|l|} 
Postmenopause (21) \\
\end{tabular} & $17(77.3 \%)$ & $4(50.0 \%)$ & \\
\hline \multirow{2}{*}{$\begin{array}{l}\text { Family history } \\
(30)\end{array}$} & \begin{tabular}{|l|} 
Positive (13) \\
\end{tabular} & $9(40.9 \%)$ & $4(50.0 \%)$ & \multirow{2}{*}{$\begin{array}{c}0.197 \\
\mathrm{P}=(0.657)\end{array}$} \\
\hline & \begin{tabular}{|l|} 
Negative (17) \\
\end{tabular} & $13(59.1 \%)$ & $4(50.0 \%)$ & \\
\hline \multirow{3}{*}{$\begin{array}{l}\text { BMI } \\
(30)\end{array}$} & Normal (5) & $5(22.7 \%)$ & $0(0.0 \%)$ & \multirow{3}{*}{$\begin{array}{c}2.240 \\
\mathrm{P}=(0.326)\end{array}$} \\
\hline & \begin{tabular}{|l|} 
Overweigh (7) \\
\end{tabular} & $5(22.7 \%)$ & $2(25.0 \%)$ & \\
\hline & Obese (18) & $12(54.5 \%)$ & $6(75.0 \%)$ & \\
\hline \multirow{2}{*}{$\begin{array}{l}\text { OCT } \\
\text { (30) }\end{array}$} & Past administration (20) & $15(68.2 \%)$ & $5(62.5 \%)$ & \multirow{2}{*}{$\begin{array}{c}0.085 \\
\mathrm{P}=(0.770\end{array}$} \\
\hline & \begin{tabular}{|l|} 
Never (10) \\
\end{tabular} & $7(31.8 \%)$ & $3(37.5 \%)$ & \\
\hline \multirow{2}{*}{$\begin{array}{l}\text { HT } \\
\text { (30) }\end{array}$} & Past administration (19) & $13(59.1 \%)$ & $6(75.0 \%)$ & \multirow{2}{*}{$\begin{array}{c}0.639 \\
\mathrm{P}=(0.424)\end{array}$} \\
\hline & \begin{tabular}{|l|} 
Never (11) \\
\end{tabular} & $9(40.9 \%)$ & $2(25.0 \%)$ & \\
\hline \multirow{3}{*}{$\begin{array}{l}\text { Type } \\
(30)\end{array}$} & IDC (20) & $14(63.6 \%)$ & $6(75.0 \%)$ & \multirow{3}{*}{$\begin{array}{c}1.705 \\
\mathrm{P}=(0.426\end{array}$} \\
\hline & \begin{tabular}{|l|} 
Mixed (6) \\
\end{tabular} & $4(18.2 \%)$ & $2(25.0 \%)$ & \\
\hline & \begin{tabular}{|l|} 
Others (4) \\
\end{tabular} & $4(18.2 \%)$ & $0(0.0 \%)$ & \\
\hline \multirow{3}{*}{$\begin{array}{l}\text { Stage } \\
\text { (30) }\end{array}$} & Stage(I) (12) & $10(45.5 \%)$ & $2(25.0 \%)$ & \multirow{3}{*}{$\begin{array}{c}1.180 \\
\mathrm{P}=(0.554)\end{array}$} \\
\hline & \begin{tabular}{|l|} 
Stage(II) (13) \\
\end{tabular} & $9(40.9 \%)$ & $4(50.0 \%)$ & \\
\hline & \begin{tabular}{|l} 
Stage(III) (5) \\
\end{tabular} & $3(13.6 \%)$ & $2(25.0 \%)$ & \\
\hline \multirow{3}{*}{$\begin{array}{l}\text { Grade } \\
\text { (30) }\end{array}$} & Grade 1 (8) & $7(31.8 \%)$ & $1(12.5 \%)$ & \multirow{3}{*}{$\begin{array}{c}2.259 \\
\mathrm{P}=(0.323\end{array}$} \\
\hline & Grade 2 (20) & $13(59.1 \%)$ & $7(87.5 \%)$ & \\
\hline & \begin{tabular}{|l|} 
Grade $3(2)$ \\
\end{tabular} & $2(9.1 \%)$ & $0(0.0 \%)$ & \\
\hline \multirow{2}{*}{$\begin{array}{l}\text { ER } \\
(30)\end{array}$} & Positive (16) & $11(50.0 \%)$ & $5(62.5 \%)$ & \multirow{2}{*}{$\begin{array}{c}0.368 \\
P=(0.544)\end{array}$} \\
\hline & \begin{tabular}{|l|} 
Negative (14) \\
\end{tabular} & $11(50.0 \%)$ & $3(37.5 \%)$ & \\
\hline \multirow{2}{*}{$\begin{array}{l}\text { PR } \\
(30)\end{array}$} & Positive (17) & $11(50.0 \%)$ & $6(75.0 \%)$ & \multirow{2}{*}{$\begin{array}{c}1.493 \\
\mathrm{P}=(0.222)\end{array}$} \\
\hline & \begin{tabular}{|l|} 
Negative (13) \\
\end{tabular} & $11(50.0 \%)$ & $2(25.0 \%)$ & \\
\hline \multirow{2}{*}{$\begin{array}{l}\text { Her2/neu } \\
(30)\end{array}$} & Positive (7) & $6(27.3 \%)$ & $1(12.5 \%)$ & \multirow{2}{*}{$\begin{array}{c}0.716 \\
P=(0.398)\end{array}$} \\
\hline & \begin{tabular}{|l|} 
Negative (23) \\
\end{tabular} & $16(72.7 \%)$ & $7(87.5 \%)$ & \\
\hline \multirow{4}{*}{$\begin{array}{l}\text { subtype } \\
(30)\end{array}$} & Luminal A (11) & $7(31.8 \%)$ & $4(50.0 \%)$ & \multirow{4}{*}{$\begin{array}{c}4.839 \\
\mathrm{P}=(0.184)\end{array}$} \\
\hline & Luminal B (8) & $5(22.7 \%)$ & $3(37.5 \%)$ & \\
\hline & \begin{tabular}{|l|} 
Basal (9) \\
\end{tabular} & $9(40.9 \%)$ & $0(0.0 \%)$ & \\
\hline & \begin{tabular}{|l} 
Her $2 /$ neu expression (2) \\
\end{tabular} & $1(4.5 \%)$ & $1(12.5 \%)$ & \\
\hline
\end{tabular}

$\mathrm{X}^{2}$ : Chi Square test,p $(>0.05)$ : not significant, *p $(<0.05)$ : significant, **p $(<0.01)$ : highly significant.

The positivity rate of IncRNA-HAGLR in sera samples was estimated among the malignant group of the study.

The positivity rate of IncRNA-HAGLR was apparently found to be higher in multipara constituting $(86.4 \%)$ compared to (13.6\%) for nullipara. Postmenopausal women constituted $(77.3 \%)$ in relation to $(22.7 \%)$ for premenopausal women.

Studying positivity rate and family history showed that $(59.1 \%)$ of those expressing IncRNAHAGLR had negative family history compared to $(40.9 \%)$ for those with positive family history. In malignant cases percent of normal BMI was (22.7\%) compared to $(22.7 \%)$ for overweight and $(54.5 \%)$ for obese women.

Results also shows that $(68.2 \%)$ and (59.1 $\%)$ were using OCT and HT respectively in the past, while $(31.8 \%)$ and $(40.9 \%)$ had never used 
OCT and HT respectively. (63.6\%) of malignant group were IDC compared to (18.2\%) for mixed IDC and ILC while other types constitute (18.2\%) of IncRNA-HAGLR positive cases.

It was found that $(45.5 \%)$ of patients were at stage (I), (40.9\%) were stage II and $(13.6 \%)$ were stage (III), While tumors with grade 3 constituted $(9.1 \%)$ compared to $(31.8 \%)$ for grade 1 and $(59.1 \%)$ for grade 2 .

The results also shows that IncRNAHAGLR positive cases with negative ER \& PR represented $(50 \%)$ compared to $(50 \%)$ for those with positive ER \& PR. The study also shows that samples with negative Her2/neu represented $(72.7 \%)$ of samples compared to $(27.3 \%)$ for those with positive Her2/neu.

The correlation between expression of IncRNA-HAGLR and different molecular subtypes of breast cancer was (31.8\%), (22.7\%), (40.9\%) and $(4.5 \%)$ with Luminal A, Luminal B, Basal and Her2/neu expression Subtype respectively.

No significant correlation was found between IncRNA-HAGLR expression and any of the investigated clinic-pathological factors $(\mathrm{P}>0.05)$ (Table 4).

\section{DISCUSSION}

Breast cancer (BC) is the most common cancer among women worldwide ${ }^{(\mathbf{1})}$, with an estimated 2.4 million new cancer cases diagnosed in $2015^{\mathbf{( 1 5 )}}$. In United States, an estimated 252,710 new cases of invasive breast cancer and 63,410 new cases of in situ breast carcinoma are diagnosed among women in $2017^{(\mathbf{1})}$. In Egypt, breast cancer accounts for $32 \%$ of total malignancies among females ${ }^{(16)}$. It also occupies the second rank of total cancer cases $(18.3 \%)^{(17)}$.

Discovering new biomarkers has been the subject of intense research especially with emergence of novel technologies. Major advances in cancer control will be greatly used in early cancer detection ${ }^{(\mathbf{1 8})}$. With the need for finding biomarkers for early detection of cancer to improve prognosis and survival ${ }^{(\mathbf{1 9})}$.

Thus the task of bioinformatics in the cancer biomarker discovery is to provide prioritized lists of marker candidates aided by availability of microarrays and bisulfite sequencing and it is anticipated that those key biomarkers identified will both represent early disease and lead to improved understanding of tumorgenesis ${ }^{(\mathbf{2 0})}$.

Breast CSCs appear to be resistant to hypoxia, chemotherapy and radiotherapy. Moreover, breast CSCs show high tumorigenicity and invasiveness, which are important to the occurrence, development, metastasis and breast cancer recurrence ${ }^{(21)}$.

Transcription factors such as OCT4, SOX2, NANOG, c-MYC and KLF4, and signaling pathways including Hedgehog, WNT, Notch, PDGF, TGF- $\beta$ and JAK/STAT, play important roles in sustaining self-renewal capacity in CSCs and therefore provide potential targets in the emergence of therapeutic strategies ${ }^{(22)}$.

In recent years, numerous studies revealed that different lncRNAs could regulate CSCs in many types of cancer via various molecular mechanisms, which include proliferation, differentiation and selfrenewal, promotion of metastasis, invasion and expecting prognosis and targeted therapies. Up to date, HOTAIR, H19, ARSR and UCA1 are the most prominent lncRNAs in CSCs. the dysregulation of IncRNAs is a potential biomarker in diagnosis, prognosis, and target therapy of cancers ${ }^{(23)}$.

The lncRNAs are group of non-coding RNAs that regulate gene expression transcriptionally and post-transcriptionally ${ }^{(24)}$.The lncRNAs are longer than 200 nucleotides and involved in the pathology of many diseases including cancers ${ }^{(25)}$. They became a subject of interest because of thier role in dysregulation in multiple types of human cancers and also they can act as prognostic markers and can be therapeutic targets ${ }^{(26)}$.

HAGLR RNA contains eight exons and its transcript is a novel lncRNA. It is transcribed from the HOXD cluster on human chromosome $2 \mathrm{q} 31.2$ in the anti-sense manner. HOXD gene is a member of the HOX cluster which regulates organogenesis and embryogenesis. HOX gene dysregulation occurs in multiple types of cancers ${ }^{(27)}$. The HOX genes are the key developmental regulators in many processes, involving apoptosis, differentiation and receptor signaling. Dysregulation of HOX genes is frequently implicated in malignancy and plays essential roles in oncogenesis and/or tumor suppression. LncNAHAGLR is included in regulating the JAK2/STAT3 signaling pathway ${ }^{(28)}$.

The results of our study revealed that IncRNAHAGLR expression was down regulated in breast cancer patients (Mean rank was 18.15) when compared 
to benign breast lesions (Mean rank was 37.75) and normal healthy control individuals (Mean rank was 40.63) where there was a highly significant difference among the three study groups as regards fold change (RQ) of serum LncRNA-HAGLR expression ( $\mathrm{P}<0.01$ ).

There was a highly significant difference between the malignant group and benign group ( $p$ $<0.01)$ by using Mann-Whitney test ( $\mathrm{U}=46.5)$, also there was a highly significant difference between the malignant group and normal control group $(\mathrm{U}=33)$ and $(\mathrm{p}<0.01)$.

Interestingly, the ROC curve for the lncRNAHAGLR gene expression in results of our study revealed a cut off value of $\leq 1.045$ to discriminate malignant from non malignant cases with a high statistical significance $(\mathrm{p}<0.001)$ where an expression level below the cutoff value is considered to be positive because lncRNA-HAGLR expression is down regulated. Using this cutoff value, 22 out of 30 malignant patients were positive ( $<$ cutoff value 1.045 ) for IncRNA-HAGLR expression (73.3\%), 1 out of 12 benign patients were positive (8.3\%) and 1 out of 12 normal individuals were positive forlncRNA-HAGLR expression $(8.3 \%)$ at $(P<0.01)$.

Thus LncRNA-HAGLR expression could be used as a sensitive biomarker for early diagnosis of $\mathrm{BC}$ with recorded sensitivity $73.3 \%$, specificity $91.6 \%$, PPV 91.6\%, NPV 73.3\% and accuracy 81.4\%.

\section{CONCLUSION}

IncRNA-HAGLR detected by quantitative RT-PCR could be used as promising biomarkers for breast cancer.

\section{REFERENCES}

1. American Cancer Society (2017): Breast Cancer Facts \& Figures. Atlanta: American Cancer Society, https://www.cancer.org/

2. Zeeneldin AA, Ramadan M, Gaber AA and Taha FM (2013). Clinico-pathological features of breast carcinoma in elderly Egyptian patients: a comparison with the non-elderly using population-based data. Journal of the Egyptian National Cancer Institute, 25(1): 511.

3. Hayes DF, Isaacs C and Stearns V (2001): Prognostic factors in breast cancer: current and new predictors of metastasis. Journal of Mammary Gland Biology and Neoplasia, 6(4): 375-392.
4. Eo HS, Heo JY, Choi Y, Hwang Y, and Choi HS (2012): A pathway-based classification of breast cancer integrating data on differentially expressed genes, copy number variations and MicroRNA target genes. Molecules and Cells, 34(4): 393-398.

5. Geng SQ, Alexandrou AT and Li JJ (2014): Breast cancer stem cells: Multiple capacities in tumor metastasis. Cancer Letters, 349(1): 1-7.

6. Kagara N, Huynh KT, Kuo C, Okano H, Sim MS, Elashoff D and Hoon DS (2012): Epigenetic regulation of cancer stem cell genes in triple-negative breast cancer. The American Journal of Pathology, 181(1): 257-267.

7. Ahmed MA, Aleskandarany MA, Rakha EA, Moustafa RZ, Benhasouna A, Nolan C and Ellis IO (2012): A CD44-/CD24+ phenotype is a poor prognostic marker in early invasive breast cancer. Breast Cancer Research and Treatment, 133(3): 979-995.

8. Dalerba P, Cho RW and Clarke MF (2007): Cancer stem cells: models and concepts. Annu. Rev. Med., 58: 267-284.

9. Phi LT, Sari IN, Yang YG, Lee SH, Jun N, Kim KS and Kwon HY (2018): Cancer Stem Cells (CSCs) in Drug Resistance and their Therapeutic Implications in Cancer Treatment. Stem Cells International, https:// www. hindawi. com/journals/sci/

10. Gibb EA, Brown CJ, and Lam WL (2011): The functional role of long non-coding RNA in human carcinomas. Molecular Cancer, 10(1): 38.

11. Spizzo R, Almeida MI, Colombatti A andCalin GA (2012): Long non-coding RNAs and cancer: a new frontier of translational research?. Oncogene, 31(43): 4577.

12. Li H, an J, Wu M, Zheng Q, GUI $X$, Li T and Lu D (2015):LncRNA HOTAIR promotes human liver cancer stem cell malignant growth through downregulation of SETD2. Oncotarget, 6(29): 27847.

13. Cheetham SW, Gruhl F, Mattick JS, and Dinger ME (2013): Long noncoding RNAs and the genetics of cancer. British Journal of Cancer, 108(12): 2419.

14. American Joint Committee on Cancer (2016): Breast. In: AJCC Cancer Staging Manual, 8th ed. New York: Springer.

15. Fitzmaurice $C$, Allen C, Barber RM, Barregard L, Bhutta ZA, Brenner $H$ and Fleming $T$ (2017): Global, regional, and 
national cancer incidence, mortality, years of life lost, years lived with disability, and disability-adjusted life-years for 32 cancer groups, 1990 to 2015: a systematic analysis for the global burden of disease study. JAMA Oncology, 3(4): 524-548.

16. Ibrahim AS, Khaled HM, Mikhail NN, Baraka $H$ andKamel $H$ (2014): Cancer incidence in Egypt: results of the national population-based cancer registry program. Journal of Cancer Epidemiology, 2014.

17. Fattah HI, Mahmoud NH, Elzoghby DM, Matar MM and EI-Shaer IM (2018): Clinical Utility of Circulating MicroRNA-21 in Breast Cancer. Egyptian Journal of Hospital Medicine, 71(4): 2950-2955.

18. Nair M, Singh Sandhu $S$ and Sharma A (2014):Prognostic and predictive biomarkers in cancer. Current Cancer Drug Targets, 14(5): 477-504.

19. Marrero JA, Feng Z, Wang Y, Nguyen MH, Befeler AS, Roberts LR and Dalhgren J (2009). $\alpha$-fetoprotein, des- $\gamma$ carboxyprothrombin, and lectin-bound $\alpha$-fetoprotein in early hepatocellular carcinoma. Gastroenterology, 137(1): 110-118.

20. Wittenberger T, Sleigh S, Reisel D, Zikan M, Wahl B, Alunni-Fabbroni M, and Lempiäinen H (2014):DNA methylation markers for early detection of women's cancer: promise and challenges. Epigenomics, 6(3): 311-327.
21. Huang X, Xiao R, Pan S, Yang X, Yuan W, Tu $Z$ and Hu W (2017): Uncovering the roles of long non-coding RNAs in cancer stem cells. Journal of Hematology \& Oncology, 10(1): 62.

22. Chi HC, Tsai CY, Tsai MM, Yeh CT and Lin KH (2017): Roles of Long Noncoding RNAs in Recurrence and Metastasis of RadiotherapyResistant Cancer Stem Cells. International Journal of Molecular Sciences, 18(9): 1903.

23. Chen $S$, Zhu J, Wang $F$, Guan $Z$, Ge $Y$, Yang $X$ and Cai $J$ (2017):LncRNAs and their role in cancer stem cells. Oncotarget, 8(66): 110685.

24. Esteller M (2011):Non-coding RNAs in human disease. Nature Reviews Genetics, 12(12): 861.

25. Leti F and DiStefano JK (2017): Long Noncoding RNAs as Diagnostic and therapeutic targets in type 2 diabetes and related complications. Genes, 8(8): 207.

26. Dykes IM and Emanueli C (2017): Transcriptional and post-transcriptional gene regulation by long non-coding RNA. Genomics, Proteomics \& Bioinformatics, 15(3): 177-186.

27. Lu C, Ma J, and Cai D (2017): Increased HAGLR expression promotes non-small cell lung cancer proliferation and invasion via enhanced de novo lipogenesis. Tumor Biology, 39(4): 697574.

28. Zheng $L$, Chen J, Zhou $Z$ and He $Z$ (2017): Knockdown of long non-coding RNA HOXDAS1 inhibits gastric cancer cell growth via inactivating the JAK2/STAT3 pathway. Tumor Biology, $\quad 39(5)$ : $\quad 705335$ 